\title{
Men and Masculinities
}

\section{Love, Fear and Disgust: Deconstructing masculinities and affective embodiment in pregnancy guides for men}

\begin{tabular}{|c|l|}
\hline Journal: & Men and Masculinities \\
\hline Manuscript ID & JMMX-19-0092.R2 \\
\hline Manuscript Type: & Original Manuscript \\
\hline Keywords: & $\begin{array}{l}\text { Material Discursive, Embodiment, Affect, Hegemonic Masculinity, } \\
\text { Pregnancy and childbirth guides, Fatherhood, Feeling, Emotion }\end{array}$ \\
\hline Abstract: & $\begin{array}{l}\text { Employing a material discursive approach this article deconstructs advice } \\
\text { within published guides to pregnancy and birth written by men for men. } \\
\text { We deconstruct the representation of feelings and emotions in men } \\
\text { during this period and debunk essentialist and social constructionist } \\
\text { views of gendered emotionality. We find the texts are saturated with } \\
\text { emotional advice, that is ambivalent and resorts to forms of essentialism } \\
\text { that obscure male vulnerabilities and leave intact male forms of power. } \\
\text { While men can expect to feel love, fear and disgust, the case for male } \\
\text { calm is reconstructed threatening dire consequences if he fails. Our } \\
\text { study makes a unique contribution to our understanding of the affective } \\
\text { assemblage that accompanies men who are now expected to care during } \\
\text { labour and birth. Men are constructed as having an embodied } \\
\text { experience that cannot be admitted to, ensuring that hegemonic } \\
\text { masculine understandings reinforce gendered constructions of care, } \\
\text { caring and emotions during pregnancy, labour and birth. }\end{array}$ \\
\hline
\end{tabular}

\section{SCHOLARONE" Manuscripts}




\section{Background}

There has been intense social scientific interest in fathering and fatherhood, following a relatively rapid social change in men's involvement in pregnancy and birth in the United Kingdom. The proportion of fathers now present at birth is $87 \%$ (but with lower proportions amongst some ethnic groups (National Perinatal Epidemiology Unit 2014) compared to 35\% in the 70s and 80s (King 2017); in many parts of the global north a man's presence at birth is arguably no longer seen as optional (Ekstöm et al. 2013). These changes are reflected in United Kingdom health policy and internationally. The National Institute for Health and Care Excellence (2014), the Department of Health (2012), the Royal College of Midwives (2011), and the World Health Organisation (2017) have all issued guidance for involving fathers in antenatal education and care, birth, and postnatal care.

Despite or perhaps because of such rapid social change, the role of men during pregnancy, labour, and birth remains far from clear. Empirical studies, primarily in Western Europe, consistently report that men feel marginalised, uncertain, and helpless, especially during labour (Chin et al. 2010; Dolan and Coe 2011; Premberg et al. 2011; Fenwick et al. 2012; Ekstöm et al. 2013; Ives 2014). We also know that men who lose control of their bodies or emotions in the birth room risk being sanctioned: told to "leave the room" (Premberg et al. 2011) or to "pull themselves together" (Draper 1997). When there are tensions between men's marginal, largely passive role and more conventional norms of masculinity associated with skilled bodily activity or calm rationality (Connell and Messerschmidt 2005), men's fears may be heightened, leaving them emotionally isolated and their embodied experience unexplored (Dolan and Coe 2011).

Childcare manuals first appeared in the early $19^{\text {th }}$ century and were addressed to both men and women. By the turn of the $20^{\text {th }}$ century, however, fathers were rarely mentioned (Lupton and Barclay 1997). Research on parenting texts have identified that men are often 
positioned as part-time, supplementary and lacking competency in caregiving, with their primary role as financial providers (Hunter et al. 2020; Sunderland, 2000). Analysis of texts for fathers who are the primary caregivers, the presentation of a 'masculine caregiving repertoire' is playful and more 'rough and tumble' (Hunter et al. 2020: 161). This legitimises their care role while preserving their masculinity. There are very few published studies of pregnancy and birth advice books (exceptions are Rodgers 2015; Kennedy et al. 2009; Sunderland 2000), but the limited literature available suggests that representations of men in pregnancy and birth guides are limited and problematic. Thomas et al.'s (2018) examination of pregnancy applications for fathers found that notions of "intimate fatherhood" are encouraged in men, and yet at the same time, their advice is trivialised. Similarly, Shiebling's (2020) analysis of "Dad Bloggers" identifies tensions in reconstructing "caring masculinities."

Research examining the rise of adaptive "nurturing" forms of masculinity or masculinities has primarily focused on how men socially construct their identities to integrate caring roles as they transition to becoming fathers (Chin et al. 2011; England and Dyck 2014; Crespi and Ruspini 2015). Such studies draw upon respondents' talk to suggest an enactment of hybrid masculinities, generating a literature that finds that "inclusive" masculinities now coexist without dominating one another (Anderson 2009; Borkowska 2020), because men are becoming more emotionally attuned (de Boise and Hearn 2017). However, hegemonic masculinity (Connell 2005), is adaptive and these studies suggest it functions in more nuanced ways by absorbing so-called feminine behaviours without radically challenging socio-economic and politically gendered inequalities.

Apart from post-hoc and vague accounts of experiencing "confusion," what this means men may actually feel, or representations of what they may expect to feel, while they navigate pregnancy, labour and birth has received little or no systematic attention. Feelings 
matter because they tell us something about material-discursive tensions and they direct our attention away from neat post-hoc cognitive social constructions that neglect gendered power relations (Borkowska 2020). When bodies and embodiment become our focus we resist the Cartesian mind-body dualism with its tendency towards an objectification of the body and instead we treat bodies and feelings as important sources of data for understanding entrenched forms of oppression as well as opportunities for empowerment. How to study feelings is, however, not without its challenges. This is because feelings and emotions can be sources of (gendered) shame that "talk" avoids.

Perhaps more than any other arena of social life, pregnancy and childbirth are treated as indubitably a woman's realm such that women are the overriding focus. Materially and therefore empirically speaking, most activity happens within and through women's bodies. However, this privileging of the woman's body is in tension with the ways men have responsibility for and to the physiological and social aspects of pregnancy and birth (Almeling and Waggoner 2013). This in turn obscures an understanding that men too will be having an embodied experience at this time (Elliot 2016). It also obscures how contemporary gendered relations interact with an arena of social life that is intimately entwined with nature and "the natural" (Garlik 2019).

The dominant emphasis on the woman in pregnancy and birthing publications, some authors of popular pregnancy guides have argued (Beaumont 2013; Sinclair 2014), has given rise to a pressing need for literature and material that is distinctively aimed at men. This need has been addressed by a number of books entering the United Kingdom market, written by men, for men. We have chosen some texts primarily designed to guide cis-gender men in heterosexual relationships about what to do, and not do, during pregnancy, labour, and birth. They are replete with advice about what to expect and "do" with feelings and as such they 
offer a rich empirical avenue into the representation of embodied masculinities, and thus provide insight into a professed "confusion."

\section{Ontology and Epistemology}

Written texts relating to heterosexual relationships can be particularly rich sources and important epistemological sites to study how gender is being constructed relationally (Sunderland 2000; Lazar 2007). We use a material-discursive analytical approach to focus on the representation of emotions and the advice given to men about managing their feelings. We treat pregnancy and birth guides as affective objects in the sense that they are designed to elicit specific emotional responses in men and draw upon wider affective assemblages of gender and emotion work (Fox and Alldred 2015).

For critical scholars of men and masculinity, emotion and embodiment is an area of growing interest (de Boise and Hearn 2017). Such research highlights assumptions about men's emotional embodied lives which deserve close examination. Feelings and emotions are felt within bodies (embodied), amid suppositions that men simply "repress" emotions (Pease 2012), which is treated as bad both for men's wellbeing (Cleary 2012) and for gender equality (Kaufman and Kimmel 2011). Rather than being an innate biological trait, emotional inexpressiveness is an effect of being socialised within a patriarchal society (Branney and White 2008). For some, the implication is that, if a lack of emotional expressiveness is socialised into men, then presumably emotional inexpressiveness could be socialised out (which would assist the pursuit of gender equality as well as promoting men's wellbeing) (Elliot 2016). If the available spaces and "permission" to express feelings or emotions are less accessible to men, then men's emotional lives matter because they tell us something about gendered systems and structures. “A fear or worry of being judged 'unmanly' by partners, peers or colleagues may actually support so-called cultural displays of "rationality"' (de Boise and Hearn 2017: 8). Anger or silence, therefore, may be deemed rational even if 
they are not progressive. This interface between felt emotion and the acceptability or unacceptability of emotional expressivity is where embodiment becomes theoretically relevant.

When men enter territory traditionally associated with women, pressure to perform discursive and representational gender work intensifies. Hegemonic masculinity - associated with "hyper-heterosexuality, control, technical/physical competence, autonomy and rationality" (Cottingham 2014: 136), or emotional detachment - becomes the discursive position that is valorised and against which men are seen to position themselves (Connell and Messerschmidt 2005). de Boise and Hearn (2017) argue that men learn to hide emotions or maintain an emotional distance as a result of being socialised to become a man. If we "belittle men's emotional competence [we] ... reinforce gender inequalities" (Holmes 2015: 180). As such, it cannot be assumed that an emotional embodied experience is present only if it is overtly expressed and articulated. A presumed lack of emotion, de Boise and Hearn (2017: 4) argue, is better explained as the absence of an overt display of emotion. "It is an inability to understand, express or communicate, rather than an inherent inability to develop emotions which men often struggle with".

This tension between what is felt and what gets articulated, de Boise (2018) argues, is conditioned by and reproduced within an array of cultural forces rather than being determined by biology. Representations of men, who assume roles traditionally associated with women and care, contribute to this affective territory. Following the "affective" or "materialist turn" points us to an examination of how power circulates through feeling and is negotiated within the public sphere, and then experienced through the body (Pedwell and Whitehead 2012; Doucet 2013). The social circulates through our bodies, but is not reducible to the individual, the personal, or the psychological. Instead, as Ahmed argues, "feelings might be how structures get under our skin" (2010: 216). This means that "men" should not be taken as an 
identity-orientated category, but rather as a social material-discursive category susceptible to de-construction (Hearn 2014; Beasley 2012). Feelings have an ontology as do representations that ideologically represent men's bodily experiences and emotions. We favour a materialist understanding whereby "bodies, things and abstractions" converge and as such we do not treat a text as analytically discrete (Fox and Alldred 2015: 2).

The absence of studies examining the representation of men's feeling and emotion during pregnancy and childbirth indicates a gap in our understanding of the affective assemblage and context in which men are now expected to be involved. Guidebooks seek to elicit desirable emotional responses in men, but within a hierarchical gender order and a context in which some emotions are deemed positive (love) and others negative (anger) (de Boise and Hearn 2017). In this paper we undertake a material-discursive analysis of affect and embodiment via pregnancy guide books as opposed to the accounts of individual subjectivities. This offers a novel way with which to theorise the tensions between men's vulnerabilities and power. Emotions are not merely subjective experiences but are a form of "disciplinary regulation" within the context of power and privilege (de Boise and Hearn 2017: 10). By deconstructing these texts with a materialist-discursive lens we see that the texts are saturated with men's emotion, both in tone and in the focus of the advice. This materialist focus will contribute to our understanding of how gendered inequalities may be lived (Macht 2020).

\section{Study Design}

If feelings have materiality, so do texts. Nature and culture are not treated as distinct realms by “new materialism" (Pedwell and Whitehead 2012; Doucet 2013). Bodies, things and abstractions do not occupy distinct spaces but have ontological status by virtue of being relational. Their materiality means they are all "agential" in the sense that they have the capacity to affect (Gregg and Siegworth 2010). "Because thoughts, ideas, feelings, desires 
and collective abstractions and 'constructions' can all materially affect and be affected by other relations in an assemblage, they can be treated in exactly the same way as other (seemingly 'more material') relations" (Fox and Alldred 2014: 125).

Deconstructing abstractions and constructions of men's emotion and feeling during pregnancy and birth enables us to examine an arena of the socio-natural assemblage that foregrounds the materiality of bodies. Drawing on a material-discursive approach in our analysis of guidebooks on pregnancy and birth for men, we sought to identify discursive representations of affect in men to better understand masculinity as a technology of embodiment (Garlick 2019). With this in mind, advice given to men about their feelings during pregnancy and childbirth offers a rich empirical vein into this discursive territory that is materially relevant.

We identified five popular guides to birth and pregnancy, written by men, for men. As our context is within the United Kingdom, both experientially and in terms of maternity care arrangements, and we and acknowledge that there are cross-cultural variations in both masculinity and fatherhood (Bridges and Pascoe 2014), we limited our focus to this geographical region. We selected the clear leaders on Amazon's bestseller list of pregnancy and birth guides written by men in the United Kingdom and marketed specifically for men. ${ }^{1}$ While we recognise the limitations of sampling texts in this way, the presence of these texts on the list suggests that the books are marketable and, at least to some extent, in current circulation. Following Illouz (2014), we would argue that their relative success reflects their resonance with their audience. Resonance, according to Illouz (2014), is achieved when a text draws on familiar cultural structures, norms, and values. Resonance can also be evoked when a text says something that is difficult to articulate, either because it defies language, it is

\footnotetext{
1 Three of the five are within the top 650 book orders for health, family and lifestyle, families, and parents as of July 2017. All five are order ranked $(380-29,179)$ well above other contenders (next on the list is at 76,808 ) also writing for expectant fathers. All five are ranked in the top five in both hard copy and Kindle version.
} 
socially unacceptable, or it addresses a social experience that is not adequately understood or categorised. Texts that resonate typically address social contradictions and offer readers guidelines that they can use in their lives. Illouz argues that popular self-help books and child-rearing books resonate in this way.

The books included in our analysis are resonant in the way they speak to norms of masculinity and to uncertainties around what men may feel. While they vary considerably in approach, emphasis and viewpoint, all five books cover pregnancy, labour and birth, giving advice to expectant fathers about the physiological processes at work, what to expect from healthcare, and what they, as men, should and should not be doing and feeling. While on the surface these books are about men becoming fathers, they are also texts about what men may expect to feel around pregnant and birthing women. It was this focus that interested us.

The five books analysed are: Rob Kemp's (2010) The Expectant Dad's Survival Guide: Everything You Need to Know; Mark Woods' (2010) Pregnancy for Men: The Whole 9 Months; Dean Baumont's (2013) The Expectant Dad's Handbook; Neil Sinclair's (2014) Commando Dad: Raw Recruits; and Mark Harris's (2015) Men, Love and Birth. The first four focus on men's expectations of fatherhood during pregnancy, as well as their role during labour and birth. With his background in midwifery, Harris's focus is preparation for birth. All five books imagine the reader to be a heterosexual, in-work man, who is relatively affluent (able to afford a "flight", and decorate "the nursery"). Sinclair does dedicate a section to young fathers, but otherwise there is little attention to the diversity of fathering and no reference to queer experiences.

The chosen texts are rich sources of explicit and implicit constructions of feelings and emotions in men during pregnancy and birth. Not only do these texts draw upon the five authors' own embodied experience of pregnancy and childbirth (as fathers, antenatal teachers, and, for one author, a midwife), but each author also has extensive working 
experience and exposure to the experiences of men-only settings (running antenatal classes for men, writing for magazines for men). This is not to suggest that these authors "faithfully" reflect the feelings of other men, only that the choices the authors make about how to construct, frame, and articulate what "should" be known speak to some broad assumptions about what men want to know and typically feel as they become fathers. Our contention is that these texts are such valuable sources about men's embodiment precisely because of their (explicit and implicit) focus on emotions.

Our analytical approach was to engage independently with the texts, reading each text over a period of months. We posed a number of questions adapted from Lupton and Barclay (1997). How are expectant fathers discursively positioned in relation to a pregnant partner? How do the authors frame and construct men's feelings, emotions, and bodies during pregnancy and birth? What assumptions are made about the gendering of feelings during pregnancy and childbirth? What is given particular attention or focus? What are the material silences and absences?

We examined the construction of men's roles in pregnancy and birth, with particular attention to how emotions and embodiment are represented. As the possibility of social sanction is high when men enter women's territory, the exploration of men's embodied experiences is fraught with methodological challenges. An interrogation of the kind proposed here offers the valuable prospect of examining what may get socially repressed, not through the frame of identity, but as a study of affect. These texts instruct men on "how to move through spaces in ways that are acceptable, normal and in concert with public expectations" (Doucet 2013: 291).

We met to discuss the emerging patterns and themes informed by our theoretical and ontological framing. We undertook an iterative process of re-reading, interpreting, and discussing. We found advice about the regulation of emotions and what to do with them was 
evident throughout the texts. We identified three themes about feelings that in our view were given most emotional charge in terms of the style, tone, and emphasis. The feelings or emotions most worthy of description and advice were love, fear, and disgust.

We also discussed our own embodied experience of reading. Reflexively, we noted that the texts were not written for us. As cis-gender women, academics and mothers, we are not addressed by the texts and found ourselves reading from the margins (Fetterley, 1997). While supportive of men's involvement in pregnancy and birth (and having given birth with the support of male partners), we both found aspects of what we were reading uncomfortable in terms of how we, as women, were being discursively depicted and constructed. At the same time, we acknowledge that pregnancy and birth guides written by women can also be complicit in reinforcing some familiar gender stereotypes.

\section{Findings}

\section{Fatherhood and Emotions: Emotion alerts!}

Each author of the five pregnancy guides signals his own credentials as a father, including admission by four authors of a lack of preparedness and feelings of regret that went with their first experience of the transition to fatherhood. Woods, a journalist, describes himself as having been "so confused” (3); Kemp, also a journalist writing for men's magazines, says, "I didn't have a clue what I was supposed to do" (10); Beaumont, initally a builder, became an antenatal educator because: "in the environment of the labour and birth I was totally out of my comfort zone. This led to memories of the birth of my son being tainted with feelings of guilt for not being better prepared" (2). Sinclair, an ex-commando and now stay-at-home dad writes: “This is the book I wish I'd been issued with when I found out I was going to be a new dad" (i). Harris, a practising midwife who runs a birth education programme for "blokes," poignantly observes: "being present at birth provokes a wide range 
of behaviours from men, from angry confrontational shouting, to becoming withdrawn and playing games on a tablet" (17). Each author talks about how it felt to be out of his comfort zone, to be uncertain and unprepared, with Harris explicitly referring to the behaviour he witnesses as a midwife which can result in feelings of "regret" and "shame." All five feel strongly enough to publish advice for the benefit of other men. This speaks to compassion and the emotional experience that leads to being "absolutely passionate about supporting dads to become better prepared for fatherhood" (Sinclair: 1).

Each author treats the "journey of fatherhood [as] an inherently emotional one" (3), but lest this emphasis on emotions is misinterpreted, they also signal their conformity with hegemonic masculine ways to show they remain "real" men. Each provide examples of this. References to "commando dad" (Sinclair: ii); "rock hard erections" (Harris: 63); "pregnancy magazines [being] insightful - not just the lingerie section" (Kemp: 74), "puerile ... humour" (Woods: 2), and "be[ing] her protector" (Beaumont: 72) explicitly signal the masculine credentials of the authors. Women's bodies are graphically described, where there is largely silence (other than reference to hormones and arousal) about men's. They seek to validate their advice and to reassure the reader that they too can be a birth companion without compromising their masculinity. Sinclair peppers his book with "Emotion Alerts!" and all the authors provide guidance "to safely navigate your way through" (Beaumont: 47).

There is something potentially radical or progressive about each text. They acknowledge that men have strong emotions and an embodied experience during pregnancy and birth. However, they ultimately fall short of subverting hegemonic masculine tropes in their construction of the pregnant and birthing woman as irrational, hyper-emotional, and in need therefore of a stoic "rock" rather than an emotionally intimate and literate partner.

Of the three emotional themes identified in the texts, love (or at least strong positive feeling) and fear were explicitly referred to across all five texts, whereas disgust was 
implicitly derived from tone and emphasis in descriptions of women's transforming, "leaky" bodies (Shildrick 1997). We found that men are instructed that love is both desirable and to be expected at birth, but that displays of love may need to be instrumentally cultivated during pregnancy. Fear, by contrast, is treated as a feeling to expect but one men should repress, for the sake of their partner and to avoid becoming a hindrance during labour. The texts seek to quell feelings of disgust by rational, physiological explanations about changes to a woman's body being a necessary part of growing "his" baby.

Feeling love: "emotions so new to you that they will knock you flat on your arse"

Fathers are told to expect a wave of positive emotions: “... the memories of the moment you became a father ... nothing even gets close to how you will feel." (Woods: 217) "Gentlemen, expect waves of huge emotions" (Sinclair: 118). Only Harris makes explicit and regular reference to feeling "love" for the woman as well as the baby. Kemp refers to the possibility that following birth some men may feel "underwhelmed," lacking emotion as a result of the "trauma" of birth (191). Love for mother and baby is framed as a "natural" response, expressed through taking on the masculine role of "protector." Both Beaumont and Harris see the "protector role" as being the masculine, bodily way to display love, so she feels calm and "safe." The plan is to utilise "natural" responses, based in evolution, that will facilitate women to produce oxytocin, a necessary hormone for birth. Harris appeals to men to use love and protection in the service of a rich and "natural" birth experience.

As well as predicting and expecting that men will feel love and "emotions so new to you that they will knock you flat on your arse" (Woods: 19) at the point of birth, their projects are concerned with persuading men to cultivate such feelings and to "care for and about" the foetus before birth. Like Harris, Woods wants to make the case that men's care for their partners has a necessary biological effect on pregnancy and birth. As such, "doing," care he concludes (with some uncertainty), must be an intrinsic part of men's nature: “[I]t seems 
almost natural for the expectant dad to start playing a more active - supportive role" to help him become focussed on his "role as a new dad" (34; our emphasis).

For the sake of their babies and themselves, men are instructed to bond prior to the arrival of the baby, and care or love becomes an affect to be treated instrumentally: "a massive impact on the bonding process for both you and your baby" [because] “... involved dads lead to more successful breastfeeding" (Beaumont: 25, 27). And if the prize of becoming an effective father with a well-bonded - and breast-fed - baby is not sufficient rationale, then self-interest is evoked:

research ... shows, the sooner we act like dads, the more chance ... we'll hang around ... the ... less likely [we will be] to suffer from depression ... and [the] more likely [we will be] to develop a strong connection with the baby (Kemp: 11).

Love for mother and baby is constructed as something to be worked on, and enacted. There is an extent to which the texts effectively instruct men to deny their own embodied experience of transitioning to fatherhood in favour of (en)acting socially expected positive emotions. Instead of being encouraged to notice and honour their materially-embodied feelings, they are coached on what they should feel, and how they should express those feelings, for the sake of the baby and the mother. Women, meanwhile, must be given free reign with their feelings and even though men can expect to become their partner's "punch bag" (Woods: 33), they must nevertheless remain "calm" (Sinclair: 99, 84).

Preparedness for birth is presented as necessary for playing the role of protector with the potential for challenges to masculinity if men feel "useless:"

It is inevitable that you are going to see her in pain and at times you may feel helpless. (Sinclair: 101)

Too many men feel ... a sense of regret or shame at not being able to "do anything" when the woman they love seemed to need them most. (Harris: 21) 
Men are warned: watching labour will feel distressing. Concerned tones suggest that what is required is necessary but not easy. His feelings must be controlled for love. A "commanding" tone drills men, because they must overcome their "inbuilt" or conventionally masculine responses.

The most important thing to remember is: don't panic! ... you have to remember that you can be a hindrance to the birthing process and your job is not to direct, but to protect. This can be easier said than done for many men due to our inbuilt "fix-it" reflex. ... In summary: listen to her, reassure her and just be there for her. (Beaumont: 75, 78-9; original emphasis)

This construction of women's need suggests that men's stoicism is to be performed as an act of care and love, for her sake and the sake of the pregnancy and baby. Each author paints a picture of a man as requiring rational evidence-based guidance and instruction to induce the required feelings and associated behaviours and in the service of preferred outcomes. Men are simultaneously urged to exert control (over themselves and their feelings) and yet avoid controlling tendencies. This combination of assumptions - that men are presumed to operate with notions of self-interested autonomy, disembodied rationality, and a desire to control - reconstructs associations of men and their feelings with hegemonic notions of masculinity. For the sake of love, presumed masculine essences are endorsed and then treated as problematic. Effectively, men are placed and embodied at the intersection of pregnancy and of birth as cultural and natural phenomena, just as women have always been, which throws into sharp relief the kinds of experiential and gender differences at play. 


\section{Feeling fear: "Gentlemen, I don't use the word 'fear' lightly"}

Fear is the predominant feeling that expectant fathers are coached to expect: fear of becoming a father, fear that they may not feel the way they are expected to feel, and fear of witnessing the birth. The authors do not mince words. Men can expect to feel "scared shitless" (Woods: 204) and "petrified” (Beaumont: 36): “Gentlemen, I don't use the word 'fear' lightly. As a commando I experienced truly frightening situations. I soon realised that I didn't fear being a dad, that was now inevitable - I feared the unknown.” (Sinclair: 1)

Kemp writes about "struggling to feel any bond or empathy with the thing growing inside her" (10). He explains he was not sure he wanted to be a dad and, in interviews with expectant fathers, describes some meeting the news of pregnancy with a "rarely voiced sense of impending doom" (19). Woods too acknowledges that feelings of fear may generate a flight response: "you may start hatching your "escape plan"” (119). All authors treat these feelings as entirely explicable and rational but also as "negative." Such feelings may be regarded as socially unacceptable, so should not be verbalised: "For the love of God do not let ... [it] ... turn into words" (Woods: 44).

Instead of treating feelings and emotions as relational, embodied, and something inherent to being human, men are instructed to engage in a form of emotional labour. Such feelings are not presented as a starting point for a conversation with their partner about what may be worrying them. Harris explicitly invokes the biological imperative: “[a man's] ... main job ... and in one form or another it's been the role of a man for thousands of years - is to keep fear at bay" (34). Men must, Beaumont stresses, "deal with them" [negative feelings] (34), although how is not expanded upon. Men just have to "act as a calming, reasoned voice of comfort" (Kemp: 51; our emphasis).

These texts suggest that this form of emotion work is appropriate and helpful for men while partners are pregnant and birthing, thus reconstructing essentialist assumptions that 
only women can be having an embodied experience of pregnancy and birth. Men are guided to suppress their own feelings through surface acting (keeping feelings intact and faking a response) and deep acting (changing internal feelings to align them appropriately with normative assumptions about what is appropriate). Kemp gives men the "advice and tips you need to make the right decisions and noises" (15; our emphasis). He recommends men should "massage the bump. Psychologically it's thought that by doing this you'll lose many of the negative thoughts you have about the baby" (Kemp: 71). Not only should men mask "negative" feelings, they should also assume responsibility for the management of their partner's emotional state. Expression of emotions and "volcanic eruptions" are treated as legitimate for women, but his task is to do his best to manage and control his partner's feelings. He is the one to "bring things down a notch or two" (Woods: 44). "It's down to you to keep her if not happy, then at least on the right side of volcanic" (Woods: 193).

This advice for men to do emotion work becomes more strident with the onset of labour. Men unable to achieve a state of "deep acting” are depicted as creating scenarios saturated with avoidable risk:

If I was to tell you that you have it within your power to affect the length of your partner's labour, the degree of pain she may or may not feel during labour, even the outcome of the birth - whether interventions are required or even whether she has a Caesarean section - how would you feel? ... it's all true. (Beaumont: 79; original emphasis)

This passage is especially interesting. First, it seeks to catch the attention of men by a direct reference to their power, and the ability to control events in the woman's body. Then there comes a set of "truths" about exactly what powers the man can wield, even unconsciously. Most telling is his question to the expectant dad: not "what do you think about that, and how might you respond as a rational bearer of male power?", but "how would you feel?" The 
appeal is not to rationality but to the bearer of relevant, embodied emotion: fear tinged with the possibility of shame or guilt.

Beaumont takes this further, reducing it to the biological: they are in animal mode and beyond surface acting. "She will smell your fear" (Beaumont: 77). A man unable to stop his fear leaking will produce the hindering influence of adrenaline in "mum," "potentially leading to a prolonged or even stalled labour" that is "more painful and more complicated" (Woods: 201) as well as causing "delayed bonding with baby" (Beaumont: 40). Beaumont suggests men unable to combat their fear should "question whether you should really be there at the birth" (36).

The advice is heavy with the implicit recognition of a materially-embodied experience, and yet the authors pull back from the full meaning of this possibility by reasserting disembodied behavioural tropes and cognitive instruction on ways of being for men. Reflecting upon the emotionally alarmist tone of what men should do with their fear, we surmise that this is because pregnancy and birth are consistently constructed as their partner's experience, even though some advice is contradictory. It is not his, but at the same time, it is his to mess up. Men are framed in disembodied ways and as cognitively plastic: "As a Commando Dad you will be tactful and empathetic" (Sinclair: 154). The notion that men are merely "supporting actors" (Woods: 154) because this is materially feminine-embodied territory constructs silence about men's relationally-embodied experience, or the possibility that the woman might want to know about how it feels for him.

\section{Feeling disgust: 'There will be blood ... and poo!'}

Material changes within and outside a woman's body are extensively detailed in Sinclair, Beaumont, Wood, and Kemp. Harris puts more emphasis on the materiality of hormonal activity. Pages of description explain what is happening within a woman's body, as 
the foetus develops. The rationale for this emphasis seems to be that men will notice and therefore might feel alarmed and even disgusted as a woman's body changes from the body that is sexually familiar to the body that is now maternal and unfamiliar. The emphasis and the tone of these sections of the text suggest shared assumptions about how men might feel about bodily changes within a woman during pregnancy and birth.

Men are warned that women will experience weight gain, absence of a waist, larger breasts, leaking breasts, breast engorgement, increased sweating, vaginal discharge, stretch marks, waddling, wind, haemorrhoids, constipation, and darkening nipples. Graphic body descriptions suggest the likelihood of, among other feelings, horror or panic about the changes to women's bodies. Any anxieties men may feel about the body failing standard tests of hegemonic femininity are not dealt with head-on. Physical changes are treated instead as merely "symptoms" of pregnancy (Sinclair: 102). “... Her nipples are darkening in colour [and] the blood supply to your partner's vagina and vulva increases in a big way from now on and they both tend to turn a purple colour, so please don't be alarmed" (Woods: 53, 84). Sinclair refers to a pregnant and birthing woman as the "Commanding Officer" or "CO" and the foetus as "Baby Trouper" or BT:" "The weight of your BT is pressing on the large blood vessels in your CO's pelvis ... this causes smaller veins in the pelvis, legs and rectum to swell" (22).

Feelings of apprehension and disquiet in men towards the leaky female body are in high evidence as earthy descriptions of what to expect during birth are put forward: “... it's almost certainly going to get ugly" (Sinclair: 100) and "... there will be blood ... Just get yourself back together as soon as possible ... As ever don’t panic" (Kemp: 157 and 165).

Men are also advised to "prepare for poo" (Woods: 211). Kemp suggests that should this happen, it could be "the bit that'll never leave your mind" even though he then advises 
"your role at this point is to ignore it completely" because "your partner shouldn't feel embarrassed for a single second" (Woods: 178, 211; our emphasis).

For a man to see the body of a woman with whom he is sexually familiar in such unexpected and challenging ways is represented as generating unsettling feelings.

These examples within texts are saturated with allusions to an embodied emotional turmoil in men as they transition toward fatherhood. Feelings of alarm, panic, and disgust about a woman's transforming body and the meanings associated with such changes suggest these emotions are both demanded and elicited from men who can expect a viscerally embodied experience. Yet to avoid the shame and guilt of acknowleging the gendered meaning of this embodied experience, advice simultaneously avoids this territory, beseeching men to keep what they feel to themselves, to perform heteronormatively, and so to maintain the veneer of hegemonic masculinity, all as an act of care.

\section{Discussion and Conclusion}

We know that men both want to, and are now expected to be, present during pregnancy and birth. Even so, they report feeling marginal and confused about their role (Premberg et al. 2011; Draper 1997). The pregnancy guides written by men that seek to prepare men for a specifically masculine role during pregnancy and labour provide guidance about what they can expect to be doing and feeling when they enter what is traditionally women's territory. Our material-discursive analysis identified the construction of three affects - love, fear, and disgust - in relation to a range of feelings men may undergo during pregnancy and birth. We then examined the extensive gendered advice about what to do with these feelings, the effect of which, we argue, is to ensure that traditional gendered assumptions about behaviour do not get destabilised.

Only women are to be permitted free reign with their (irrational) emotions, whereas men should stoically bear "female" eruptions, suppressing feelings of fear and channelling 
calm rationality, while also averting a critical "gaze" from a body that will fail the tests of hegemonic femininity (Price and Shildrick 1997: 3). To aid their feeling management, men may conceive of themselves as "protectors" - strong, capable, in control. Love may erupt at birth, but is construed in instrumental terms during pregnancy as a positive and necessary feeling that should be cultivated primarily for the sake of the foetus (soon to be "his" baby). Such advice about what men should do with feelings is reconstructed as the masculine way to "do" his love or "care" during pregnancy and birth (Connell and Messerschmidt 2005;

Doucet and Lee 2014; England and Dyck 2014).

In writing emotions into the enactment of a masculine role, the texts are potentially progressive. However, we found that the authors implicitly give men permission to "cleave" to men's conventional ways of being to "conceal inner emotional turmoil" (Holmes 2015). As men's bodies do not undergo the same upheaval and given the texts' essentialist assumptions that men are rational (and therefore unemotional) or at least should be emotionally inexpressive, a set of "feeling rules" are constructed. These are based upon a hierarchy of "need" (de Boise and Hearn 2017), in which those with visible "symptoms" and thus legitimate expressive feelings must take priority. These "feeling rules" are rationalised but accompanied by highly emotive language, often in alarmist tones, exhorting men to induce or inhibit "correct" feelings. The authors are strident in their advice. Despite the core recommendation that embodied men should enter this female territory they nevertheless instruct men: by all means feel, but on no account fully feel and certainly do not show or express your "negative" feelings.

By constructing some emotions as positive and others as negative, they leave both the emotional vulnerabilities of men unaddressed and the Cartesian associations of the body and emotions with irrationality and women intact (de Boise 2018). Such gendered textual advice forms part of an affective assemblage of "feeling rules" that recommend stoicism, emotional 
control, and manipulation together with cultural displays of rationality (de Boise and Hearn 2017).

While these texts make a discursive attempt to resonate with men who undoubtedly want to engage with and be involved in pregnancy, labour, and birth - with all the benefits that this is thought to bring to the family unit - their advice is not suggestive of a more "inclusive" form of masculinity (Anderson 2009). On the surface the books appeal to hybrid forms of masculinities. Sinclair relies on militaristic metaphors, Kemp speaks to a heteronormative sexualised man, Woods is the comic, Beaumont's men are the "protectors," whereas for Harris they are "lovers." What unites them however, is a reliance on thin advice for men to construct rationalist forms of control over their emotions in order to enact a form of care. Arguably this advice is "functionally rational in a patriarchal, capitalist system" (de Boise and Hearn 2017: 8). By drawing on hegemonic masculine tropes to support men to manage embodied experiences within the gendered space of pregnancy and childbirth, their advice functions to protect the cis-gender, heterosexual men who are imagined as their primary audience from the shame of being associated with devalued marginalised bodies, behaviour, and identities (Scheff 2003). Emotional repression, as Doucet (2013) argues, remains a powerful way to maintain bourgeois colonial patriarchal privilege.

If the disciplinary regulation of emotions "affect our understanding of our bodies in contradistinction to other(ed) bodies" (de Boise and Hearn 2017, 10), then pregnancy and childbirth are affective moments that typically empirically invite either essentialist explanation or social constructionist critique. Neither are adequate. Garlik (2019) cautions against becoming "mired in debates over essentialism" (385) because in so doing we "position masculinity solely as the socially constructed other to nature" (390). If the production of men and women as properly masculine or feminine mean masculinity gets 
"established via the domination of nature" (386) even if that nature is ours, then advice to control emotions writes men's vulnerabilities out and their power in.

Pregnant and birthing women and nature too easily get conflated, as if woman is also nature. In contrast, an epistemology of embodiment would suggest that representations focussing on the body-reflexive practices of masculinities, during pregnancy and childbirth, may in fact be "bio-political techniques for the reduction or management of the complexity of embodied life" (390). The acknowledged tensions identified in representations of feelings men may expect while attending pregnancy and birth point to possible patterns of embodiment and affect in men. To advise men to have feelings but not reveal them, and then claim that this is both the rational and loving thing to do, is to divert attention from the sociopolitical work that such disciplinary regulation performs. In so doing these texts remain conservative manifestos that we argue go some way to illuminate (even if, we suggest, they ultimately fail to alleviate) the "confusion" men report.

We limited our study to a United Kingdom cultural context, recognising that both emotionality and fathering are not homogenous across national and cultural contexts (Macht 2020). Future research might usefully address how the tensions between masculinity, emotionality, and men's involvement in pregnancy and birth are materially and discursively constructed and managed in other cultural contexts.

\section{References}

Ahmed, S. 2010. The Promise of Happiness London: Duke University Press.

Almeling, R. \& Waggoner, M. R. (2013) More and Less Than Equal: How Men Factor in the Reproductive Equation Gender \& Society 27 (6): 821-842.

Anderson, E. 2009. Inclusive Masculinity: The Changing Nature of Masculinities New York: Taylor \& Francis.

Beasley, C. 2012. Problematizing contemporary Men/Masculinities theorizing: the 
contribution of Raewyn Connell and conceptual-terminological tensions today The British Journal of Sociology 63 (4): 747-765.

Beaumont, D. 2013. The expectant Dads handbook, London: Vermillion.

Borkowska, K. 2020. Approaches to studying masculinity: A nonlinear perspective of theoretical paradigms. Men and Masculinities 23 (3-4), 409-424.

Branney, P. and White, A. 2008. Big boys don't cry: Depression and men Advances in Psychiatric Treatment 14, 256-262.

Bridges, T. and Pascoe, C. J. 2014. Hybrid Masculinities: New Directions in the Sociology of Men and Masculinities Sociology Compass 8 (3) 246-258.

Chin R, Hall P, and Daiches A. 2011. Fathers' experiences of their transition to fatherhood: a metasynthesis. Journal of Reproductive and Infant Psychology 29 (1): 4-18.

Cleary, A. 2012. Suicidal action, emotional expression, and the performance of masculinities. Social Science \& Medicine, 74, 498-505.

Connell, R. W. 2005. Masculinities 2nd ed Cambridge, UK: Polity Press.

Connell, R. W. and Messerschmidt, James W., 2005. Hegemonic Masculinity: Rethinking the Concept Gender and Society 19 (6): 829-859.

Cottingham, M.D., 2014. Recruiting men, constructing manhood: How health care organizations mobilize masculinities as nursing recruitment strategy. Gender \& Society 28 (1): 133-156.

Crespi, I and Ruspini, E. (2015) Transition to fatherhood: New perspectives in the global context of changing men's identities International Review of Sociology 25 (3): 353358.

de Boise, S. 2018. The personal is political ... just not always progressive: affective interruptions and their promise for CSMM NORM: International Journal for Masculinity Studies 13:3-4: 158-174. 
de Boise, S. and Hearn, J. 2017. Are men getting more emotional? Critical sociological perspectives on men, masculinities and emotions. The Sociological Review 65(4): 118.

Department of Health. 2012. Preparation for birth and beyond: a resource pack for leaders of community groups and activities. Accessed 16 Sept, 2020.

https://www.gov.uk/government/publications/preparation-for-birth-and-beyond-aresource-pack-for-leaders-of-community-groups-and-activities

Dolan, A. and Coe, C. 2011. Men, masculine identities and childbirth. Social Health and Illness 33 (7): 1019-34.

Doucet, A. 2013. A 'Choreography of Becoming': Fathering, Embodied Care, and New Materialisms Canadian Review of Sociology 50 (3) 284-305.

Doucet, A. \& Lee, R. 2014. Fathering, Feminism(s) Gender, and Sexualities: connections, Tensions and New Pathways Journal of Family theory \& Review 6 (4) 355-373.

Draper, J. 1997. Whose welfare in the labour room? A discussion of the increasing trend of fathers' birth attendance. Midwifery 13 (3) 132-8.

Ekstőm, A., Arvidsson, K., Falkenstőm, M. and Thorstensson, S. 2013. Fathers' Feelings and Experiences during Pregnancy and Childbirth: A Qualitative Study. Journal of Nursing Care, 2 (2) 136-140.

Elliott, K. 2016. Caring Masculinities: Theorizing an Emerging Concept Men and Masculinities 19 (3) 240-259.

England, K. and Dyck, I. 2014. Masculinities, Embodiment and Care. In Masculinities and Place, edited by Gorman-Murray, A. and Hopkins, P, 285-298. Farnham, Surrey: Ashgate Publishing Limited. 
Fenwick, J., Bayes, S. and Johansson, M. 2012. A Qualitative Investigation Into Pregnancy Experiences and Childbirth Expectations of Australian Father-to-be Book. Sexual \& Reproductive Health Care, 3 (1): 3-9.

Fetterley, J. 1997. Introduction: on the politics of literature. In Feminisms: an anthology of literary theory and criticism, edited by Robyn, R. Warhol and Diane Price Herndl, 564-573. New Brunswick, New Jersey: Rutgers University Press.

Fox, N. J. and Alldred, P. 2014. Inside the Research-Assemblage: New Materialism and Micropolitics of Social Inquiry Sociological Research Online 20 (2), 6.

Garlick, S. 2019. The Return of Nature: Feminism, Hegemonic Masculinities, and New Materialisms. Men and Masculinities, 22 (2): 380-403.

Gregg, M. and Siegworth, G., eds. 2010. The affect theory reader Durham, NC: Duke University Press.

Harris, M. 2015. Men Love and Birth London: Pinter and Martin Ltd.

Hearn, J. 2014. Men, masculinities and the material(-)discursive NORMA: International Journal for Masculinity Studies 9 (1) 5-17.

Holmes, M. 2015. Men's Emotions: Heteromasculinity, Emotional Reflexivity, and Intimate Relationships Men and Masculinities 18 (2) 176-192.

Hunter, S.C., Riggs, D.W., and Augoustinos, M. 2020. Constructions of primary caregiving fathers in popular parenting texts. Men and Masculinities 23 (1), 150-169.

Illouz, E. 2014. Hard-Core Romance: Fifty Shades of Grey, Best-Sellers, and Society. London: University of Chicago Press.

Ives, J. 2014. Men, maternity and moral residue: negotiating the moral demands of the transition to first time fatherhood. Sociology of Health \& Illness 36 (7): 1003-1019.

Kaufman, M. \& Kimmel, M. 2011. The Guy's Guide to Feminism Berkeley, CA: Seal Press. 
Kemp, R. 2010. The expectant dad's survival guide: Everything you need to know. London: Vermilion.

Kennedy, H. P., Nardini, K., Mcleod-Waldo, R. and Ennis, L. 2009. Top-Selling Childbirth Advice Books: A Discourse Analysis. Birth, 36 (4): 318-324.

King, L. 2017. Hiding in the Pub to Cutting the Cord? Men's Presence at Chidlbirth in Britain c. 1940s-2000s Social History of Medicine 30 (2): 389-407

Lazar, M.M. 2007. Feminist Critical Discourse Analysis: Articulating a feminist discourse praxiz. Critical Discourse Studies 4 (2), 141-164.

Lupton, D. and Barclay, L. 1997. Constructing Fatherhood: Discourses and Experiences. London: Sage Publications.

Macht, A. 2020. Resisting the commodification of intimate life? Paternal love, emotional bordering and narratives of ambivalent family consumerism from Scottish and Romanian fathers. Families, Relationships and Societies 9 (2), 303-3019.

National Institute for Health and Care Excellence 2014. Intrapartum care: Care of healthy women and their babies during childbirth. NICE guidelines [CG190]. London: National Institute for Health and Care Excellence.

National Perinatal Epidemiology Unit (NPEU) 2014. "Safely Delivered: A National Survey of Women's Experiences of Maternity Care.” Accessed July 2, 2015.

\section{www.npeu.ox.ac.uk/downloads/files/reports/Safely\%20delivered\%20NMS\%202014.pdf}

Pease, B. 2012. The politics of gendered emotions: Disrupting men's emotional investment in privilege Australian Journal of Social Issues 47, 125-142.

Pedwell, C and Whitehead, A. 2012. Affecting feminism: Questions of feeling in feminist theory Feminist Theory 13 (2) 115-129.

Premberg, A., Carlsson, G., Hellstrom, A. L. and Berg, M. 2011. First-time fathers' experiences of childbirth--a phenomenological study. Midwifery 27 (6): 848-53. 
Price, J. and Shildrick, M. 2017. Openings on the body: A critical introduction. In Feminist theory and the body: a reader, edited by Price, J and Shildrick, M., 1-14. London: Routledge

Rodgers, O. 2015. "Relinquish the reins": Persuasion and consensus in the discourse of pregnancy and childbirth advice literature. Women and Birth 28 (1): 40-46.

Royal College of Midwives. 2011. Reaching Out: Involving Fathers in Maternity Care. Accessed 16 Sept 2020. https://www.rcm.org.uk/media/2343/reaching-out-involvingfathers-in-maternity-care.pdf

Scheff, T. 2003. Shame in Self and Society Symbolic Interaction 26 (2) 239-262.

Scheibling, C. 2020. "Real Heroes Care”: How Dad Blogers Are Recongstructing Fatherhood and Masculinities. Men and Masculinities 23(1): 3-19.

Shildrick, M. 1997. Leaky Bodies and Boundaries: Feminism, Postmodernism and (Bio)Ethics. London: Routledge

Sinclair, N. 2014. Commando Dad: Raw Recruits, London: Hodder \& Stoughton Ltd.

Sunderland, J. 2000. Baby Entertainer, Bumbling Assistant and Line Manager: Discourses of Fatherhood in Parentcraft Texts. Discourse \& Society, 11 (2): 249-274.

Thomas, G.M., Lupton, D. and Pedersen, S. 2018. 'The appy for a happy pappy’: expectant fatherhood and pregnancy apps. Journal of Gender Studies 1-12.

World Health Organisation 2017. Accessed February 13, 2017. http://www.euro.who.int/_data/assets/pdf_file/0017/69011/E91129.pdf?ua=1

Woods, M. 2010. Pregnancy for men: The whole 9 months. White Ladder Press Ltd. 